\title{
Questionnaire study of use of emergency contraception among teenagers
}

\author{
Elise Kosunen, Andres Vikat, Matti Rimpelä, Arja Rimpelä, Heini Huhtala
}

Easy accessibility and availability of emergency contraception raises contradictory opinions. Education about emergency contraception is resisted because of a fear that it might lead to irresponsible sexual behaviour and repeated use of emergency contraception instead of regular contraception. ${ }^{1}$

In Finland, sales of emergency contraception (the Yuzpe method) increased 10-fold from 1987 to the mid-1990s. In 1994 a national survey among 18-44 year old women showed that knowledge and use of the method was concentrated in the youngest respondents. ${ }^{2}$ Reports from other countries confirm that young women and even teenagers are well aware of the method. ${ }^{3}$ However, only a few reports have been published on use of emergency contraception among adolescents. We studied knowledge of emergency contraception and frequency of use among teenagers.

\section{Participants, methods, and results}

The school health promotion study was introduced to provide data on adolescent health behaviours in Finland. Regional and local school authorities were told about the study, and 96 out of 452 municipalities joined it in 1996. Pupils anonymously completed a structured questionnaire during one lesson under the supervision of their teacher and enclosed the questionnaire in an envelope directed to the research group.

The total number of respondents was 52700 , and the response rate was $88-91 \%$ for comprehensive schools and $82 \%$ for upper secondary schools. We report here data on girls in comprehensive schools born in 1981 (mean age 14.8 years, range 14.3-15.2) and 1980 (15.8 years, range 15.3-16.2) and girls in upper secondary schools born in 1978 (17.8 years, 17.3-18.2); the total number of girls was 21940.

The question on emergency contraception asked: "Have you ever used emergency contraception?" Alternative responses were: (1) No; (2) Yes. How many times altogether? Number of times? or (3) I do not know what emergency contraception is. The questionnaire also asked whether the respondent had ever had sexual intercourse.

Only 3\% of the $14-15$ year olds and $1.5 \%$ of the 17 year olds did not know what emergency contraception was (table). The proportion of girls who had used emergency contraception increased with age from $2.1 \%$ to $15.1 \%$. About two thirds of all girls who had used emergency contraception had used it only once (table). The proportion of multiple users did not suggest any systematic increase with age.

In comprehensive schools, $13.3 \%$ of 14 year olds and $28.8 \%$ of 15 year olds had had sexual intercourse at least once, while among 17 year olds the prevalence was $51.5 \%$.

\section{Comment}

In Finland, emergency contraception is delivered as a part of primary health care in local health centres and family planning clinics. ${ }^{5}$ Adolescents get information on contraception in sex education lessons at schools. School health care advises on problems of sexuality, including need of emergency contraception.

The adolescent girls were widely aware of emergency contraception, which is consistent with results for younger women in other countries. ${ }^{3}{ }^{4}$ We only asked about knowledge of the existence of the method: the results may not indicate that adolescents were well informed of details of its use. British studies have shown that although adolescents know about emergency contraception, they are unclear how to obtain the pills and how to use them. ${ }^{34}$

Emergency contraception has not become a contraceptive choice replacing conventional methods among adolescents. Only a small proportion of teenagers had used emergency contraception repeatedly. Our results suggest that easy access to contraceptive services (including emergency contraception) and intensive sex education have not increased adolescent sexual activity. The proportion of sexually experienced teenagers in our study was not higher than in Finnish studies in the late 1980 s or early 1990 s when emergency contraception was not widely used.

Contributors: EK participated in planning the questionnaire, formulated the present study, and had main responsibility for writing the paper. She is the study guarantor. AV and $\mathrm{HH}$ carried out the statistical analyses. MR initiated and designed the school health promotion study, organised collection and recording of data, and participated in analysis of data. AR participated in planning the study and analysing data. The results were interpreted and the paper was written jointly by all authors.

Funding: Ministry of Social Affairs and Health has supported the study from the health promotion fund. Local municipalities have financed the data collection at schools. Competing interests: None declared.

1 Stubblefield R. Self-administered emergency contraception-a second chance. N Engl J Med 1998;339:41-2.

2 Kosunen E, Sihvo S, Hemminki E. Knowledge and use of hormona emergency contraception in Finland. Contraception 1997;55:153-7.

3 Smith B, Gurney E, Aboulela L, Templeton A. Emergency contraception: a survey of women's knowledge and attitudes. Br J Obstet Gynecol 1996;103:1109-16.

4 Graham A, Green L, Glasier AF. Teenagers' knowledge of emergency contraception: questionnaire survey in south east Scotland. BMJ 1996;312:1567-9.

5 Rimpela M, Rimpela A, Kosunen E. From control policy to comprehensive family planning: success stories from Finland. Int J Health Promotion Educ 1996;3:28-32.

(Accepted 19 January 1999)

Knowledge and use of emergency contraception by age. Values are numbers (percentages)

\begin{tabular}{lcccc} 
& \multicolumn{4}{c}{ Age (years) } \\
\cline { 2 - 5 } & $\mathbf{1 4}$ & $\mathbf{1 5}$ & $\mathbf{1 7}$ & All \\
\hline Use of emergency contraception: & \multicolumn{5}{c}{} \\
\hline Ever used & $173(2.1)$ & $509(6.3)$ & $729(15.1)$ & $1411(6.6)$ \\
\hline Never used & $7875(93.6)$ & $7365(91.5)$ & $4039(83.5)$ & $19279(90.5)$ \\
\hline Don't know what it is & $368(4.3)$ & $177(2.2)$ & $72(1.4)$ & $617(2.9)$ \\
\hline Total & 8416 & 8051 & 4840 & 21307 \\
\hline Number of uses among ever users (distribution): & 61.8 & 62.9 & 66.4 & 64.6 \\
\hline Once & 16.2 & 16.7 & 17.6 & 17.1 \\
\hline Twice & 6.4 & 4.3 & 4.9 & 4.9 \\
\hline Three or more & 15.6 & 16.1 & 11.1 & 13.5 \\
\hline Missing & & & &
\end{tabular}

\author{
Department of \\ General Practice, \\ Medical School, \\ University of \\ Tampere, PO Box \\ 607, FIN-33101 \\ Tampere, Finland \\ Elise Kosunen, \\ senior lecturer in \\ general practice \\ Tampere School of \\ Public Health, \\ University of \\ Tampere, \\ Andres Vikat, \\ research fellow \\ Arja Rimpelä, \\ professor in \\ community health \\ Heini Huhtala \\ lecturer in \\ epidemiology \\ National Research \\ and Development \\ Centre for Welfare \\ and Health, PO Box \\ 220, FIN-00531 \\ Helsinki, Finland \\ Matti Rimpelä, \\ professor
}

Correspondence to: Dr Kosunen meelko@uta.fi

BMJ 1999;319:91 